\title{
Gesundheitspolitischer Rückblick auf die Herbstsession
}

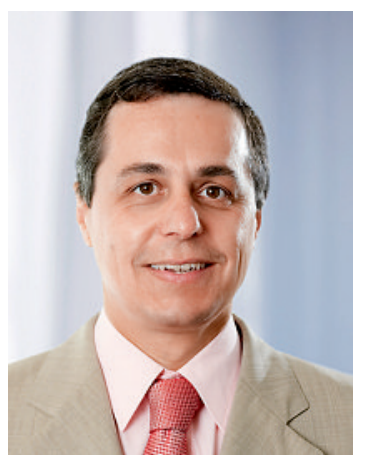

Ignazio Cassis
Zwei Ereignisse kennzeichneten die letzte Session der Eidgenössischen Räte: die Wahl des Nachfolgers von Bundesrat Pascal Couchepin und die Beratungen zu den dringlichen Massnahmen zur Eindämmung der Krankenversicherungskosten.

Am 1. April dieses Jahres skandierten Ärztinnen und Ärzte auf verschiedenen Plätzen der Schweiz die Parole «Couchepin, go home!» In einigen Tagen geht dieser Wunsch nun in Erfüllung: Couchepin zieht sich ins Wallis zurück. Nun stellt sich folgende Frage: «Was wird sich mit Didier Burkhalter ändern?» Wird er die Entscheide von Pascal Couchepin in den Bereichen Labor und Medikamente umstossen? Das bezweifle ich stark. Wie alle Gesundheitsminister der Industrieländer steht auch der Minister eines reichen Landes wie der Schweiz vor der gleichen Herausforderung: Das finanzielle Gleichgewicht des Gesundheitssystems muss erhalten werden. Diese Herausforderung muss auch Didier Burkhalter bewältigen, dem die FMH «viel Kraft und Mut» wünscht! Während die Grundlagen wahrscheinlich gleich bleiben, könnte sich der Stil ändern: denn Didier Burkhalter ist nicht Pascal Couchepin. Wir müssen ihn nun kennenlernen. Mit der frischen Energie des Neulings wird er sich Zeit nehmen, um seinen Beamten, den Akteuren, den Gesundheitsdirektoren und den Konsumenten zuzuhören. Und er wird sich Zeit nehmen, um die ungeheure Komplexi- lichkeitsrecht verankert, um die Blockierung durch ein Referendum zu verhindern. Dies führte zu einer langwierigen Debatte: Die Akteure, die Kantone, die Wirtschaft, die Gewerkschaften und die Patientinnen und Patienten mussten für diese Übung einen Teil ihrer Ferien opfern. Das Ziel bestand darin, diese Fragen in der Herbstsession zu erledigen, um das Jahr 2010 mit den entsprechenden Änderungen und weniger hohen Prämien beginnen zu können. Daraus wird aber nichts! Die Räte haben den Bettel hingeworfen und die

\section{Während die Grundlagen wahrschein- lich gleich bleiben, könnte sich der Stil ändern}

Prüfung des Dossiers auf die Wintersession verschoben. So konnten wir uns im Nationalrat einen ersten Überblick verschaffen, was zu folgendem Ergebnis führte: streichen, streichen und nochmals streichen. Alles, was auf den ersten Blick genial erschien, hielt einer eingehenden Analyse nicht stand: Die Praxisgebühr von Fr. 30.- wurde fallengelassen ebenso wie die zusätzliche Prämienverbilligung von 200 Millionen, die Planung des spitalambulanten Bereichs, die interkantonale Vereinheitlichung des Taxpunktwerts TARMED, die Pflicht, das preisgünstigste Generikum zu erstatten, usw. Dieser harten Auslese entging nur wenig: die telefonische Konsultation, die Verlängerung auf drei Jahre für Verträge mit höherer Franchise, das Werbeverbot... Kurz gesagt: Der Berg hat eine ganz kleine Maus geboren, und das

\section{Die Ankündigung eines schockierenden Anstiegs der Krankenkassenprämien löste einen unvergleichlichen politischen Aktivismus aus. Im Nationalrat hat der Berg nur eine ganz kleine Maus geboren, und das ganze Spektakel kann man mit Fug und Recht als «Pflästerlipolitik» bezeichnen}

tät des Gesundheitssystems zu verstehen und die demagogischen Sirenengesänge der Anhänger des «Man muss nur...» zu durchschauen. Viel Glück, Herr Bundesrat!

Nachfolgend ein Beispiel zu den Vertretern des «Man muss nur ...», mit dem diese Haltung gut zum Ausdruck kommt. Im letzten April wurde für 2010 ein schockierender Anstieg der Krankenkassenprämien angekündigt, was einen unvergleichlichen politischen Aktivismus auslöste. Diesen Sommer versuchten sich zahlreiche Politikerinnen und Politiker als Ärzte, die das Gesundheitssystem heilen wollen. So wurden zuerst in den Medien und anschliessend in den parlamentarischen Kommissionen (das entspricht nun der Regel!) nicht weniger als 40 Vorstösse lanciert - alle im Dring- ganze Spektakel kann mit Fug und Recht als «Pflästerlipolitik» bezeichnet werden. So funktioniert die Politik. Schon Otto von Bismarck - der Erfinder unseres Krankenversicherungssystems - hatte im 19. Jahrhundert die Politik als «die Kunst des Möglichen» bezeichnet!

Zum Glück läuft nicht alles auf diese Weise. Abgesehen vom erwähnten Sommerspektakel führen (praktisch) die gleichen Politikerinnen und Politiker ihre Arbeit - seriös und konstruktiv - im Hinblick auf eine tiefgreifende Reform der ambulanten Medizin weiter. Das geschieht weit entfernt vom ganzen Medienrummel!

Dr. med. Ignazio Cassis Nationalrat und Vizepräsident der FMH 